\title{
Multicolor interphase cytogenetics for the study of plasma cell dyscrasias
}

\author{
BORJA SÁEZ ${ }^{1,2}$, JOSÉ I. MARTÍN-SUBERO ${ }^{2}$, MARÍA D. ODERO ${ }^{1,3}$, FELIPE PROSPER ${ }^{4}$, \\ JUAN C. CIGUDOSA ${ }^{5}$, ROBERT SCHOCH ${ }^{6}$, MARÍA J. CALASANZ ${ }^{1}$ and REINER SIEBERT ${ }^{2}$ \\ ${ }^{1}$ Department of Genetics, University of Navarra, Pamplona, Spain; ${ }^{2}$ Institute of Human Genetics, University \\ Hospital Schleswig-Holstein, Campus Kiel, Kiel, Germany; ${ }^{3}$ Laboratory of Genetics, Division of Oncology, \\ Center for Applied Medical Research, University of Navarra, Pamplona; ${ }^{4}$ Oncology Area, Area of \\ Cell Therapy and Hematology Service, University Clinic, University of Navarra and Foundation for \\ Applied Medical Research, Pamplona; ${ }^{5}$ Molecular Cytogenetics Group, Spanish National \\ Cancer Research Centre (CNIO), Madrid, Spain; ${ }^{6}$ Second Department of Medicine, \\ University Hospital Schleswig-Holstein, Campus Kiel, Kiel, Germany
}

Received April 23, 2007; Accepted June 4, 2007

\begin{abstract}
Specific chromosomal abnormalities such as chromosome 13 deletions and some translocations affecting the immunoglobulin heavy chain $(I G H)$ gene, namely $\mathrm{t}(4 ; 14)(\mathrm{p} 16 ; \mathrm{q} 32)$ and $\mathrm{t}(14 ; 16)(\mathrm{q} 32 ; \mathrm{q} 23)$ have been associated with an adverse prognosis in multiple myeloma. Conventional cytogenetic techniques fail to detect these aberrations in the majority of cases. Thus, we have developed a novel set of interphase fluorescence in situ hybridization (I-FISH) assays targeting those regions frequently lost on chromosome 13 as well as those oncogenes most recurrently involved in translocations with the $I G H$ locus in multiple myeloma, i.e. IRTA1/2 (1q21), FGFR3/MMSET (4p16), CCND3 (6p21), IRF4 (6p25), CCNDI (11q13), MAF (16q23), and MAFB (20q12). The probes were combined in a multicolor fashion to develop novel multicolor I-FISH (MI-FISH) assays, whose validity and applicability was evaluated in negative controls and in a series of 13 plasma cell neoplasias. Additionally, a combination of the novel MI-FISH assays with staining for the plasma cell-specific antigen VS38c by means of multicolor FICTION (M-FICTION, fluorescence immunophenotyping and interphase cytogenetics as a tool for the investigation of neoplasms) allowed us to selectively analyze the plasma cell compartment, and thereby to increase the assay sensitivity.
\end{abstract}

Correspondence to: Dr Borja Sáez, Department of Genetics, University of Navarra, Irunlarrea s/n, 31008 Pamplona, Navarra, Spain

E-mail: bsaezoch@alumni.unav.es

Key words: multiple myeloma, in situ hybridization, fluorescence immunophenotyping, interphase cytogenetics

\section{Introduction}

Partial or complete losses of chromosome 13 and translocations affecting chromosomal band $14 \mathrm{q} 32$ containing the immunoglobulin heavy chain $(I G H)$ locus have been reported to be the most common cytogenetic features in multiple myeloma (MM) and monoclonal gammopathy of unknown significance (MGUS) (1,2). Chromosome 13 abnormalities comprise mainly monosomy 13 (3) but also small interstitial deletions in chromosomal band 13q14 (4). These are detectable in $50-86 \%$ of cases $(2,4,5)$. In contrast to many other B cell neoplasms, IGH translocations in $\mathrm{MM}$ affect a great variety of partner loci. The most recurrent $I G H$ partners, together, present in $40 \%$ of MM (6), are chromosomal bands 1q21 (IRTA1/IRTA2), 4p16 (FGFR3/MMSET), 6p21 (CCND3), 6p25 (IRF4), 11q13 (CCND1), 16q23 (MAF) and 20q12 $(M A F B)(7)$. Several studies have suggested an association of chromosome 13 aberrations as well as some $I G H$ translocations with unfavorable outcome both in patients treated with conventional or high-dose chemotherapy $(8,9)$.

Due to the pathogenetic and prognostic impact of genetic aberrations in plasma cell dyscrasias (PCD) and in order to facilitate the diagnostic process, we developed and validated a new set of fluorescence in situ hybridization (FISH) probes for the detection of chromosome 13 abnormalities and for the most recurrent translocations affecting $I G H$ loci in these diseases. We have shown the applicability of these probe sets for multicolor interphase (MI) cytogenetics. Moreover, by combining the novel MI-FISH assays with staining for the VS38c antigen according to the M-FICTION (multicolorfluorescence immunophenotyping and interphase cytogenetics as a tool for the investigation of neoplasms) technique $(10,11)$, we have provided a highly sensitive means for the simultaneous study of morphological, immunophenotypic and genetic features of PCD at the single-cell level. 


\section{Materials and methods}

Patients and controls. Tumor samples from the bone marrow of $12 \mathrm{MM}$ were analyzed in the present study. Eight of them were cytogenetically reported as normal. In one case (no. 3) no metaphases were obtained, whereas in another case (no. 4) no material was available for karyotyping. Cases no. 11 and 12 showed complex karyotypes. Additionally, the plasma cell leukemia (PCL)-derived cell line JJN3 was studied (12) (Table I). In 10 cases, we previously detected breakpoints affecting the $I G H$ locus by means of double-color FISH using the LSI IGH break-apart probe (Abbott/Vysis, Downer Grove, IL, USA). Cytogenetic suspensions left from routine tumor cytogenetic analyses were used for MI-FISH analysis, whereas bone marrow smears were utilized for M-FICTION studies. All MM primary cases were retrieved from the cytogenetic database of the Department of Genetics of the University of Navarra in Pamplona, Spain, and the Institute of Human Genetics of the University Hospital Schleswig-Holstein Campus Kiel, Kiel, Germany. Peripheral blood mononuclear cells from healthy individuals with normal karyotype served as the negative controls. This study was performed within the context of the G03/136 Red temática FIS: 'Mieloma Múltiple y otras Ganmapatías', Spanish Ministry of Health, for which the approval of the Review Board was obtained.

Clone selection. Bioinformatic resources available at NCBI (http://www.ncbi.nlm.nhi.gov) and the University of California at Santa Cruz (version, May 2004) (http://www.genome. ucsc.edu) were utilized to select appropriate clones. All probes for the detection of $I G H$ chromosomal rearrangements were designed in a way that they flanked the most recurrent breakpoints of the respective translocation described so far (Table II). The probes for the detection of chromosome 13 abnormalities were localized within the critical regions commonly deleted in PCD (Table III) (4). As internal control a probe for chromosome band 13q34 spanning STS marker D13S327 was selected.

Besides newly established probes, the LSI IGH dual-color break-apart rearrangement probe, LSI IGH-CCND1 dualcolor dual-fusion translocation probe and LSI IGH-MYCCEP8 triple-color dual-fusion translocation probe (all from Abbott/Vysis) were applied. For the detection of CCND3 breakpoints a previously published FISH assay was used (13).

Probe preparation, FISH and multicolor FISH. Clones were cultured overnight in LB media supplemented with the appropriate antibiotic (chloramphenicol for BAC clones and kanamycin for PAC clones). DNA was prepared using the Perfectprep DNA Plasmid Maxi kit (Eppendorf, Köln, Germany). Clone DNAs were labelled with dUTP-Spectrum Orange (SO, Abbott/Vysis), dUTP-Spectrum Green (SG, Abbott/Vysis), dUTP-Texas Red (TR, Molecular Probes, OR, USA), dUTP-Cyanine5 (Cy5, Amersham Biosciences, UK) and dUTP-DEAC (NEN, Zaventem, Belgium) by random priming reaction (Bioprime, Life Technologies, Karlsruhe, Germany) exchanging the dNTP-Bio with the appropriate dNTP mixture. Labelled products were purified with Sephadex G-50 columns. Two hundred ng of each probe was coprecipitated with $5 \mu 1$ of Cot1-DNA (Life
Technologies) and re-suspended in $9 \mu 1$ of master mix containing $2 \mathrm{X} \mathrm{SSC}, 50 \%$ formamide and $10 \%$ dextran sulfate. Additionally, $1 \mu 1$ of the proper commercial probe was added to the noncommercial probe mixture. FISH was performed as previously described (14). Slides were counterstained with DAPI and mounted in antifade solution. For dual-color and multicolor experiments, respectively, hybridization signals were analyzed by use of a Zeiss Axioskop 2 fluorescence microscope (Zeiss, Göttingen, Germany) with suitable filter sets (AHF, Tübingen, Germany) and documented using ISIS imaging system (Meta-Systems, Altlussheim, Germany) or a motorized fluorescence microscope (Axioplan 2 imaging mot, Zeiss) equipped with narrow band-pass filters and MetaSystems isis/mFISH imaging system (11).

Determination of cut-off levels for false-positive findings. For the determination of the diagnostic thresholds of the new probe sets, 200 nuclei were evaluated in each of five normal controls. In order to define precisely a 'split', the distance between the differently colored signals of a signal pair within the nucleus was estimated in relation to the signal diameter by visual inspection (14). The diagnostic cut-offs were calculated as the mean of false positives in the controls plus three times the standard deviation (SD) (15).

Multicolor FICTION (M-FICTION). For M-FICTION, staining with the monoclonal antibody (MoAb) VS38c that labels normal and neoplastic plasma cells (DakoCytomation, Glostrup, Denmark) was combined with the multicolor probe sets for the detection of IGH translocations and $13 \mathrm{q}$ deletions in PCD. Bone marrow smears were thawed and air-dried for $30 \mathrm{~min}$ at room temperature (RT), fixed in acetone for $10 \mathrm{~min}$ and air-dried. Slides were incubated for $30 \mathrm{~min}$ at RT with the primary MoAb anti-VS38c (1:20), diluted in PNM buffer $\left(0.1 \mathrm{M} \mathrm{NaH}_{2} \mathrm{PO}_{4} \cdot 2 \mathrm{H}_{2} \mathrm{O}\right.$ and $0.1 \mathrm{M} \mathrm{Na}_{2} \mathrm{HPO}_{4} \cdot 2 \mathrm{H}_{2} \mathrm{O}$ ).

Fluorescence detection was performed with a sequential cascade of three Alexa Fluor 350-conjugated Abs (Molecular Probes) diluted in PNM buffer (1:50) for $30 \mathrm{~min}$ each at RT; Alexa 350-conjugated rabbit anti-mouse; Alexa 350conjugated goat anti-rabbit; and Alexa 350-conjugated donkey anti-goat. After immunophenotyping, slides were fixed in Carnoy's fixative (methanol:acetic acid, 3:1) for $10 \mathrm{~min}$ and in paraformaldehyde solution (1\%) for $1 \mathrm{~min}$. Then slides were dehydrated through increasing ethanol concentrations $(70 \%, 85 \%$ and absolute) and air-dried. The multicolor probe pool $(1.3 \mu 1)$ was applied to the bone marrow smear and covered with a round $10-\mathrm{mm}$ coverslip. Both probe and target DNA were simultaneously denatured at $70^{\circ} \mathrm{C}$ for $7 \mathrm{~min}$ and incubated overnight at $37^{\circ} \mathrm{C}$. Posthybridization washes were performed in $0.1 \mathrm{X}$ SSC three times for $5 \mathrm{~min}$ each at $60^{\circ} \mathrm{C}$. Then, slides were washed once in PN buffer and mounted in antifade solution. Image acquisition was performed using the same equipment cited above (11).

\section{Results and discussion}

Negative control studies. All probes (Tables II and III) hybridized to the correct chromosomal location in normal metaphases and gave two intense hybridization signals in 
Table I. Clinical and cytogenetic features of the plasma cell dyscrasias studied by multicolor interphase cytogenetics.

\begin{tabular}{|c|c|c|c|c|c|c|c|}
\hline \multirow{2}{*}{$\begin{array}{l}\text { Case } \\
\text { no. }\end{array}$} & \multirow{2}{*}{$\begin{array}{l}\text { Age } \\
\text { (years) }\end{array}$} & \multirow[t]{2}{*}{ Gender } & \multirow[t]{2}{*}{ Karyotype } & \multicolumn{4}{|c|}{ Interphase FISH results ${ }^{\mathrm{a}}$} \\
\hline & & & & IGH break apart ${ }^{\mathrm{b}}$ & $\begin{array}{l}\text { Oncogene } \\
\text { fused to } I G H\end{array}$ & $13 q$ & $\begin{array}{l}\text { Deleted } \\
\text { region in 13q }\end{array}$ \\
\hline 1 & 69 & Male & $46, X Y$ & $\begin{array}{l}\text { nuc ish } 14 \mathrm{q} 32(I G H \text {-cen } \times 2, \\
I G H \text {-tel } \times 1)[15 \%]^{\mathrm{e}}\end{array}$ & $C C N D 1$ & $\begin{array}{l}\text { nuc ish } 13 \mathrm{q}(R B 1 \times 2, \\
\text { D13S319 } 2 \text { 2, D13S25 x } 2, \\
\text { D13S327 x 2) }\end{array}$ & None \\
\hline 2 & 67 & Male & $46, X Y$ & $\begin{array}{l}\text { nuc ish } 14 \mathrm{q} 32(I G H \text {-cen } \times 2, \\
\text { IGH-tel x 1) }[32 \%]^{\mathrm{e}}\end{array}$ & CCND1 & $\begin{array}{l}\text { nuc ish } 13 \mathrm{q}(R B 1 \times 2, \\
\text { D13S319 } 2 \text { 2, D13S25 × } 2, \\
\text { D13S327 } 2 \text { 2) }\end{array}$ & None \\
\hline 3 & 82 & Female & No metaphases & $\begin{array}{l}\text { nuc ish } 14 \mathrm{q} 32(I G H \text {-cen } \times 2 \text {, } \\
I G H \text {-tel x 2) }(I G H \text {-cen } \\
\text { sep } I G H \text {-tel x1) }[15 \%]\end{array}$ & $C C N D 1$ & $\begin{array}{l}\text { nuc ish } 13 \mathrm{q}(R B 1 \times 2, \\
\mathrm{D} 13 \mathrm{~S} 25 \times 2, \mathrm{D} 13 \mathrm{~S} 319 \times 2 \\
\mathrm{D} 13 \mathrm{~S} 327 \times 2)\end{array}$ & None \\
\hline 4 & 66 & Male & ND & ND & $C C N D 1^{\mathrm{d}}$ & $\begin{array}{l}\text { nuc ish } 13 \mathrm{q}(R B 1 \times 2, \\
\text { D13S319 } 2 \text { 2, D13S } 25 \times 2, \\
\text { D13S327 } 2 \text { 2) }\end{array}$ & None $^{d}$ \\
\hline 5 & 60 & Female & $46, X X$ & $\begin{array}{l}\text { nuc ish } 14 \mathrm{q} 32(I G H \text {-cen } \times 2, \\
I G H \text {-tel } \times 1)[30 \%]^{\mathrm{e}}\end{array}$ & $\begin{array}{l}\text { FGFR3/ } \\
\text { MMSET }\end{array}$ & $\begin{array}{l}\text { nuc ish } 13 \mathrm{q}(R B 1 \times 1, \\
\text { D13S319 } 1 \text { 1, D13S25 x } 1 \text {, } \\
\text { D13S327 x 1) [30\%] }\end{array}$ & Monosomy 13 \\
\hline 6 & 74 & Female & $46, X X$ & $\begin{array}{l}\text { nuc ish } 14 \mathrm{q} 32(I G H \text {-cen } \times 2 \text {, } \\
I G H \text {-tel } \times 2)(I G H \text {-cen } \\
\text { sep } I G H \text {-tel } \times 1)[11 \%]\end{array}$ & $\begin{array}{l}\text { FGFR3/ } \\
\text { MMSET }\end{array}$ & $\begin{array}{l}\text { nuc ish } 13 \mathrm{q}(R B 1 \times 1, \\
\text { D13S319 } 1, \text { D13S25 } 1 \text {, } \\
\text { D13S327 } 1)[25 \%]\end{array}$ & Monosomy 13 \\
\hline 7 & 66 & Female & $46, X X$ & $\begin{array}{l}\text { nuc ish } 14 \mathrm{q} 32(I G H \text {-cen } \times 2 \text {, } \\
I G H \text {-tel } \times 2)(I G H \text {-cen } \\
\text { sep } I G H \text {-tel x } 1)[9 \%]\end{array}$ & $M Y C$ & $\begin{array}{l}\text { nuc ish } 13 \mathrm{q}(R B 1 \times 2, \\
\text { D13S319 } 2 \text { 2, D13S25 x } 2, \\
\text { D13S327 x 2) }\end{array}$ & None \\
\hline 8 & 63 & Female & $46, X X$ & $\begin{array}{l}\text { nuc ish } 14 \mathrm{q} 32(I G H \text {-cen } \times 2, \\
I G H \text {-tel } \times 2)(I G H \text {-cen } \\
\text { sep } I G H \text {-tel x1) }[15 \%]\end{array}$ & Not detected & $\begin{array}{l}\text { nuc ish } 13 \mathrm{q}(R B 1 \times 1, \\
\text { D13S319 } 1, \text { D } 13 \mathrm{~S} 25 \times 1, \\
\text { D13S327 } 1 \text { 1) [27\%] }\end{array}$ & Monosomy 13 \\
\hline 9 & 72 & Male & $46, X Y$ & $\begin{array}{l}\text { nuc ish } 14 \mathrm{q} 32(I G H \text {-cen } \times 2 \text {, } \\
I G H \text {-tel x } 2)(I G H \text {-cen } \\
\text { sep } I G H \text {-tel x1) }[2 \%]\end{array}$ & Not detected & $\begin{array}{l}\text { nuc ish } 13 \mathrm{q}(R B 1 \times 2, \\
\text { D13S319 } 2 \text { 2, D13S25 x 2, } \\
\text { D13S327 x 2) }\end{array}$ & None \\
\hline 10 & 37 & Female & $46, X X$ & $\begin{array}{l}\text { nuc ish } 14 \mathrm{q} 32(I G H \text {-cen x } \\
2-3, I G H \text {-tel x 1) [13\%] }\end{array}$ & Not detected & $\begin{array}{l}\text { nuc ish } 13 \mathrm{q}(R B 1 \times 1, \\
\text { D13S319 } 1, \text { D } 13 \mathrm{~S} 25 \times 1, \\
\text { D13S327 x 2) [27\%] }\end{array}$ & $\begin{array}{c}R B 1 \\
\mathrm{D} 13 \mathrm{~S} 319 \\
\mathrm{D} 13 \mathrm{~S} 25\end{array}$ \\
\hline 11 & 68 & Male & $\begin{array}{l}49, X,- \\
Y, i(1)(\mathrm{q} 10) \operatorname{der}(1) \mathrm{t}(1 ; 3) \\
(\mathrm{q} 23 ; \mathrm{q} 13),+5, \operatorname{add}(5)(\mathrm{q} 23), \\
\operatorname{del}(5)(\mathrm{q} 33),+7,+15 / 49, \\
\text { idem,dup(2)(p13p14) }\end{array}$ & $\begin{array}{l}\text { nuc ish } 14 \mathrm{q} 32(I G H \text {-cen } \times 2, \\
I G H \text {-tel x } 2)(I G H \text {-cen } \\
\text { sep } I G H \text {-tel x } 1)[85 \%]\end{array}$ & IRF4 & ND & ND \\
\hline 12 & 79 & Female & $\begin{array}{l}\text { c } 45, X X, \operatorname{del}(1)(\mathrm{p} 13), \operatorname{der}(3), \\
\mathrm{t}(3 ; 6)(\mathrm{p} 25 ; \mathrm{q} ?), \operatorname{der}(6) \mathrm{t}(\mathrm{X} ; 1 ; 6) \\
(? ; ? ; \mathrm{p} 25 ; \mathrm{q} ?), \operatorname{der}(9) \mathrm{t}(7 ; 9) \\
(\mathrm{q} ? ; \mathrm{p} 11.2),-13 \mathrm{t}(14 ; 20) \\
(\mathrm{q} 32 ; \mathrm{q} 11.2)\end{array}$ & ND & $M A F B$ & ND & ND \\
\hline $\begin{array}{l}\text { JJN3 } \\
\text { Ref. } \\
\text { (12) }\end{array}$ & 57 & Female & $\begin{array}{l}58-67<3 \mathrm{n}>\mathrm{XX},+1,-2,+5,+8, \\
+8,-9,-11,-12,-13,-15,-17, \\
+20, \operatorname{add}(1)(\mathrm{p} 22), \operatorname{der}(1) \\
\mathrm{t}(1 ; ? 3)(\mathrm{q} 41 ; \mathrm{p} 26) \times 2, \operatorname{add}(3) \\
(\mathrm{p} 26), \operatorname{add}(5)(\mathrm{p} 15) \times 1-2, \\
\mathrm{i}(5 \mathrm{p}), \operatorname{del}(6)(\mathrm{q} 13), \operatorname{del}(7)(\mathrm{q} 32), \\
\operatorname{der}(7) \mathrm{t}(7 ; 11)(\mathrm{q} 36 ; \mathrm{q} 13), \mathrm{add} \\
(8)(\mathrm{p} 1 ?) \times 2, \mathrm{t}(12 ; 19)(\mathrm{p} 13 ; \\
\mathrm{q} 13) \operatorname{der}(14) \operatorname{add}(14)(\mathrm{p} 11) \\
\mathrm{t}(14 ; 16)(\mathrm{q} 32 ; \mathrm{q} 23), \mathrm{t}(14 ; 16) \\
(\mathrm{q} 32 ; \mathrm{q} 23), \operatorname{der}(16) \mathrm{t}(14 ; 16) \\
(\mathrm{q} 32 ; \mathrm{q} 23), \operatorname{del}(22)(\mathrm{q} 12)\end{array}$ & ND & $M A F$ & ND & ND \\
\hline
\end{tabular}

aDescribed according to the ISCN-95 guidelines; cen, probe located centromeric to the gene; tel, probe located in the telomeric part of the gene; ND, not done. ${ }^{b}$ LSI IGH dual-color, break-apart rearrangement probe (Abbot/Vysis). Cut-off level for false-positive findings was 1\%. ${ }^{c}$ Described by SKY FISH. ${ }^{\mathrm{d} D e t e c t e d}$

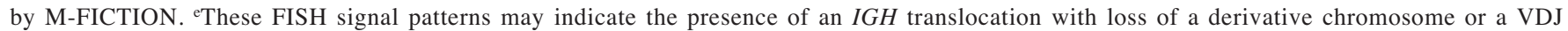
recombination affecting telomeric sequences of the $\mathrm{V}_{\mathrm{H}}$ region. 
Table II. Clones for the IRTA1/2, FGFR3/MMSET, IRF4, MAF and MAFB loci selected for the present study.

\begin{tabular}{|c|c|c|c|c|c|}
\hline $\begin{array}{l}\text { Chromosome } \\
\text { band }\end{array}$ & Locus & Clone & Location to breakpoint & Start $^{\mathrm{a}}(\mathrm{bp})$ & End $^{a}(b p)$ \\
\hline \multirow[t]{7}{*}{ 1q21 } & IRTAI/2 & RP11-110J1 & Centromeric & $153,785,333$ & $153,952,624$ \\
\hline & & RP11-85G21 & Centromeric & $153,995,561$ & $154,177,585$ \\
\hline & & RP11-217A12 & Centromeric & $154,198,015$ & $154,333,751$ \\
\hline & Breakpoint region (16) & & & $154,380,777$ & $154,380,943$ \\
\hline & & RP11-367J7 & Telomeric & $154,428,798$ & $154,589,153$ \\
\hline & & RP11-120D12 & Telomeric & $154,589,054$ & $154,652,686$ \\
\hline & & RP11-444M10 & Telomeric & $154,716,835$ & $154,906,311$ \\
\hline \multirow[t]{4}{*}{$4 \mathrm{p} 16$} & FGFR3/MMSET & CTD-3056L2 & Centromeric & $2,079,777$ & $2,245,075$ \\
\hline & & RP11-1132M4 & Centromeric & $1,925,106$ & $2,088,258$ \\
\hline & Breakpoint region (17) & & & $1,824,392$ & $1,872,576$ \\
\hline & & RP11-572O17 & Telomeric & $1,592,782$ & $1,782,006$ \\
\hline \multirow[t]{5}{*}{$6 \mathrm{p} 25$} & IRF4 & RP5-856G1 & Centromeric & 940,429 & $1,092,223$ \\
\hline & & RP5-1077H22 & Centromeric & 835,761 & 929,128 \\
\hline & Breakpoint region (18) & & & $140 \mathrm{~kb} 3$ ' to IRF4 & $460 \mathrm{~kb} 5$ ' to IRF4 \\
\hline & & & & IRF4 (start: 336,739 & end: 356,442$)$ \\
\hline & & RP3-416J7 & Telomeric & 89,702 & 213,735 \\
\hline \multirow[t]{6}{*}{$16 \mathrm{q} 23$} & $M A F$ & RP11-571O6 & Centromeric & $76,153,174$ & $76,329,694$ \\
\hline & & RP11-264M12 & Centromeric & $76,287,998$ & $76,447,922$ \\
\hline & & RP11-281J9 & Centromeric & $76,434,195$ & $76,606,528$ \\
\hline & Breakpoint region $(17,19)$ & & & $76,906,953$ & $77,635,456$ \\
\hline & & RP11-70D24 & Telomeric & $78,125,034$ & $78,290,954$ \\
\hline & & RP11-345M22 & Telomeric & $78,289,994$ & $78,477,920$ \\
\hline \multirow[t]{5}{*}{$20 q 12$} & $M A F B$ & RP4-616B8 & Centromeric & $36,983,660$ & $37,139,038$ \\
\hline & & RP3-404H4 & Centromeric & $37,410,145$ & $37,566,011$ \\
\hline & Breakpoint region (20) & & & $37,565,916$ & $38,231,797$ \\
\hline & & RP4-644L1 & Telomeric & $38,657,866$ & $38,803,458$ \\
\hline & & RP1-94E24 & Telomeric & $38,886,168$ & $39,028,514$ \\
\hline
\end{tabular}

aPosition in base pairs according to UCSC Genome Browser (version, May 2004). Numbers in parentheses behind breakpoint regions indicate references.

interphase nuclei. Clones mapping centromeric and telomeric of the breakpoints of the IRTA1/2, FGFR3/MMSET, IRF4, $M A F$ and $M A F B$ loci were differentially labelled in SO or SG, pooled for each locus, and hybridized onto negative controls. Based on the signal patterns observed in these controls, a 'split' was uniformly defined for all of the break-apart assays as a spatial separation of signals flanking a given locus of more than three times the signal diameter as estimated by visual inspection. Using these criteria, the cut-off levels were $2.2 \%$ for IRTA $1 / 2,2.6 \%$ for FGFR3/MMSET, $3.0 \%$ for IRF $4,2.7 \%$ for $M A F$ and $1.7 \%$ for MAFB. Clones within the commonly deleted regions in chromosome 13 were labelled in a multicolor fashion (Table III). Applying this probe set to normal controls, a cut-off was established for all signal constellations observed suggesting a deletion within the critical region in 13q14. The cut-off levels for all these patterns were $<2 \%$.

Multicolor interphase FISH: assay design. Due to technical considerations and previous experience we aimed to label each probe with a single dye rather than using combinatorial labeling, as this approach renders routine evaluation of the hybridization signals easier. The limitation of widely available fluorescence dyes restricted our labeling scheme to 6 colors (5 different fluorescent dyes plus DNA counterstain). Thus, we proposed a sequential, two-step procedure which took into account the prevalence of the different $I G H$ translocations in PCD (Table IV). The first MI-FISH included probes for FGFR3/MMSET, MAF and CCND3 in combination with the commercial probe LSI IGH/CCND1. This assay detects the most frequent and prognostically important IGH translocations in MM. The second MI-FISH assay included probes for $I R F 4, I R T A I / 2$ and $M A F B$ in combination with the commercial LSI IGH break-apart probe. The MI-FISH design is summarized in Table IV. A balanced rearrangement affecting $I G H$ and any oncogene under study should normally lead to a double split and a double colocalization of the $I G H$ probe with the locus-specific probe for the oncogene involved in the rearrangement (Fig. 1a, d and e). It is worth noting that in both MI-FISH assays, in addition to typical signal constellations, variant hybridization patterns including gains and losses of derivative and normal chromosomes as well as changes in ploidy may occur in interphase cells (Fig. 1b and c). 
Table III. Selected clones spanning the RB1 locus and the STS markers D13S319, D13S25 and D13S327 for the present study and the fluorescent dyes used for the MI-FISH/FICTION PCD 13q assay.

\begin{tabular}{|c|c|c|c|c|c|c|c|}
\hline Chromosome & Locus spanned & Start $^{\mathrm{a}}$ (bp) & End $^{a}(b p)$ & Clone & Start $^{\mathrm{a}}(\mathrm{bp})$ & End $^{a}(b p)$ & Fluorescent dye \\
\hline \multirow[t]{8}{*}{$13 q 14$} & $R B 1$ & $47,775,911$ & $47,954,023$ & RP11-305D15 & $47,760,579$ & $47,897,921$ & $\mathrm{SO}$ \\
\hline & & & & RP11-174I10 & $47,897,822$ & $47,960,646$ & \\
\hline & D13S319 & $49,603,317$ & $49,603,487$ & RP11-34F20 & $49,478,678$ & $49,633,565$ & SG \\
\hline & & & & RP11-480P3 & $49,633,466$ & $49,719,243$ & \\
\hline & & & & RP11-369L4 & $49,719,144$ & $49,850,074$ & \\
\hline & D13S25 & $50,143,128$ & $50,143,379$ & RP11-175B12 & $49,973,084$ & $50,099,510$ & DEAC \\
\hline & & & & RP11-58C16 & * & $50,191,416$ & \\
\hline & & & & RP11-233H19 & $50,187,167$ & $50,328,618$ & \\
\hline \multirow[t]{2}{*}{$13 q 34$} & D13S327 & $114,040,208$ & $114,040,462$ & RP11-245B11 & $113,770,458$ & $113,932,864$ & TR \\
\hline & & & & RP11-569D9 & $113,930,806$ & $114,103,243$ & \\
\hline
\end{tabular}

aPosition in base pairs according to UCSC Genome Browser (version, May 2004). (*) Only one BAC end sequence is available.

Table IV. Sequential procedure for the detection of the most frequent $I G H$ translocations in PCD.

\begin{tabular}{lccc}
\hline & Probes & Fluorescent dye & Translocations \\
\hline MI-FISH/FICTION & LSI IGH-CCND1 & SO and SG & $\mathrm{t}(11 ; 14)(\mathrm{q} 13 ; \mathrm{q} 32)$ \\
PCD IGH assay 1 & (Abbott/Vysis) $^{\mathrm{a}}$ & & $\mathrm{t}(4 ; 14)(\mathrm{p} 16 ; \mathrm{q} 32)$ \\
& FGFR3/MMSET & TR & $\mathrm{t}(14 ; 16)(\mathrm{q} 32 ; \mathrm{q} 23)$ \\
& MAF & DEAC & $\mathrm{t}(6 ; 14)(\mathrm{p} 21 ; \mathrm{q} 32)$ \\
MI-FISH/FICTION & LSI IGH break apart & Cy5 & $\mathrm{t}(14 \mathrm{q} 32)$ \\
PCD IGH assay 2 & (Abbott/Vysis) & \\
& IRF4 & SO and SG & $\mathrm{t}(6 ; 14)(\mathrm{p} 25 ; \mathrm{q} 32)$ \\
& IRTAI/IRTA2 & TR & $\mathrm{t}(1 ; 14)(\mathrm{q} 21 ; \mathrm{q} 32)$ \\
& $M A F B$ & DEAC & $\mathrm{t}(14 ; 20)(\mathrm{q} 32 ; \mathrm{q} 12)$ \\
\hline
\end{tabular}

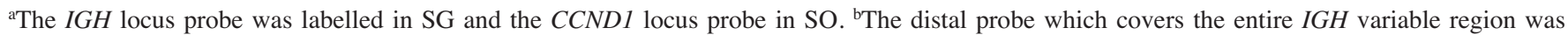
labelled in SG. The proximal probe which lies 3' (centromeric) to the $I G H$ locus was labelled in SO.

For the $13 \mathrm{q}$ MI-FISH assay (Table III), the loss of one signal from the probes spanning the RBI gene, D13S319 or D13S25 STS markers would imply a 13q14 deletion (Fig. 1i), whereas the signal pattern constellation indicating a monosomy 13 would also include loss of the signals derived from the clones spanning the telomeric internal control (STS D13S327) at 13q34 (Fig. 1h).

Due to the miniaturized hybridization format, it is, in principle, possible to perform up to 12 multicolor hybridizations on a single slide. Therefore, all three MI-FISH assays described here were performed simultaneously on a single slide (11). Moreover, a commercially available MIFISH probe (Abbott/Vysis) for the detection of hyperdiploid MM, may be added (21).

MI-FISH in PCD with breakpoints at 14q32. In order to establish the diagnostic validity and applicability of our new IGH loci MI-FISH assays, we evaluated 12 primary MM and the PCL-derived cell line JJN3. Ten cases were previously shown to carry breakpoints affecting $I G H$ loci by means of double-color FISH (Table I). Additionally, a t(14;20) (q32;q11.2) was detected by means of Spectral Karyotyping (SKY) in case no. 12 suggesting the involvement of the IGH loci. Similarly, the JJN3 cell line was previously reported to carry a $\mathrm{t}(14 ; 16)(\mathrm{q} 32 ; \mathrm{q} 23)$ by means of G-banding analysis (12). Finally, bone marrow smears in case no. 4 were held in reserve for the M-FICTION assays.

In 8 out of the $12 \mathrm{MM}$, the partner gene involved in the $I G H$ translocation was detected with the novel MI-FISH assays. Four cases, nos. 1-4 (case no. 4 detected by MFICTION), displayed an aberrant signal constellation suggesting the presence of a $t(11 ; 14)(q 13 ; q 32)$ (Fig. 1c). Cases no. 5 and 6 , showed a signal constellation indicating a $\mathrm{t}(4 ; 14)(\mathrm{p} 16 ; \mathrm{q} 32)$ translocation affecting the FGFR3/MMSET genes (Fig. 1a). The PCL-derived cell line JJN3 displayed four fusions of the probes for $I G H$ (SG) and MAF (DEAC) indicating the presence of a $\mathrm{t}(14 ; 16)(\mathrm{q} 32 ; \mathrm{q} 23)$. Additionally, extra copies of the derivative chromosomes 14 or 16 and supernumerary signals for CCND1, FRFG3/MMSET, MAF and $I G H$ indicated polyploidy (Fig. 1b). Cases no. 11 and 12 displayed the typical signal constellation suggesting the presence of $\mathrm{t}(6 ; 14)(\mathrm{p} 25 ; \mathrm{q} 32)$ and $\mathrm{t}(14 ; 20)(\mathrm{q} 32 ; \mathrm{q} 11)$ 


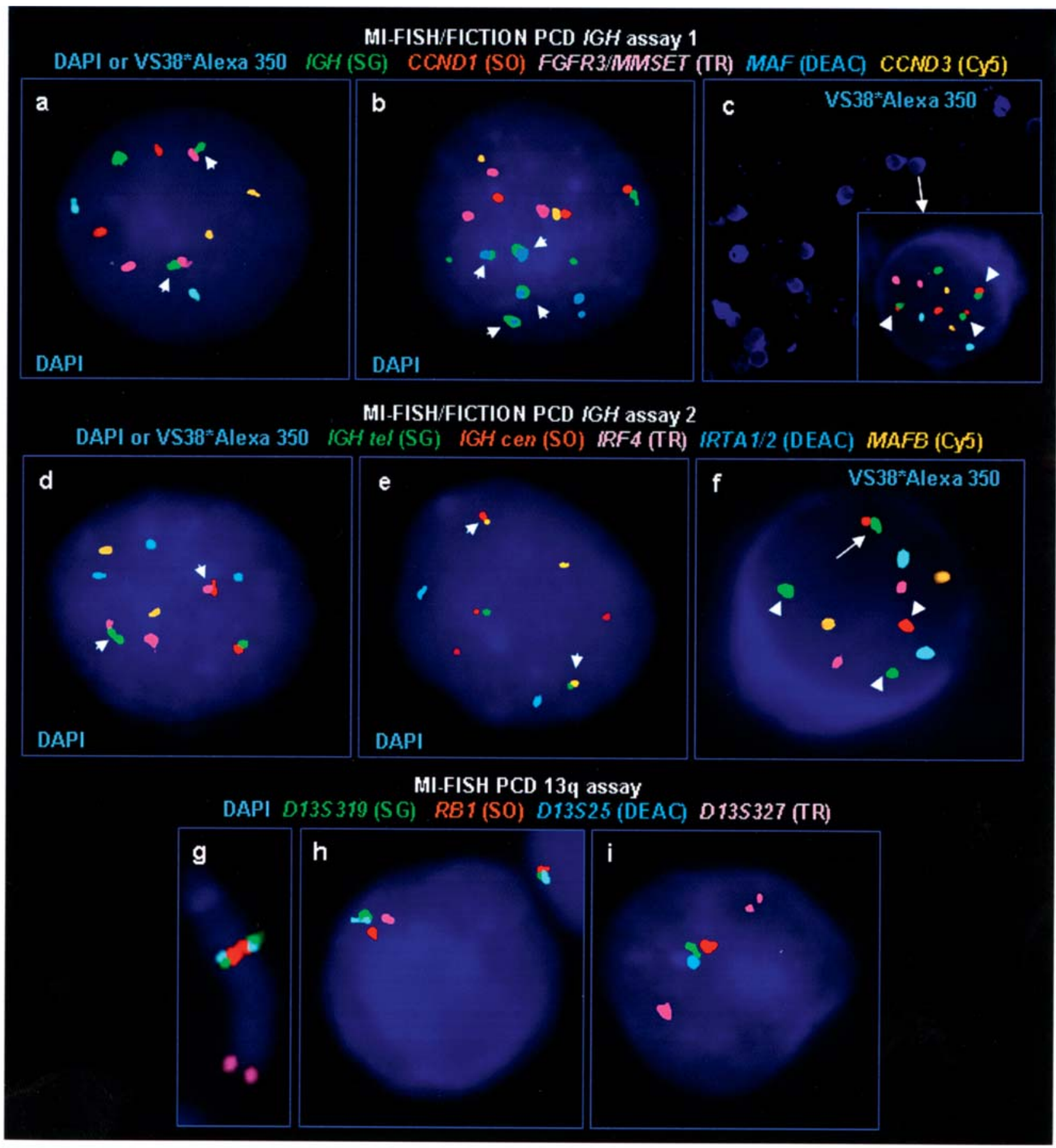

Figure 1. Multicolor interphase cytogenetics for the detection of IGH translocations and 13q deletions in plasma cell dyscrasias (PCD). Notice that MI-FISH and M-FICTION images are shown using a false-color display. FISH probes for the different PCD assays are color-typed according to their fluorescent staining (red scripts, SO labeling; green, SG labeling; light blue, DEAC labeling; pink, TR labeling; orange, Cy5 labeling; and dark blue, DAPI or Alexa fluor 350 staining). (a-c) MI-FISH/FICTION PCD IGH assay 1 include probes for $I G H, C C N D 1, F G F R 3 / M S E T, M A F$ and $C C N D 3$. (a) The interphase nucleus from case no. 6 shows a double fusion of the probes for IGH (SG) and FGFR3/MMSET (TR) indicating the presence of a t(4;14)(p16;q32). (b) The interphase nucleus from the JJN3 cell line shows four fusions (arrows) of the probes for $I G H(\mathrm{SG})$ and $M A F$ (DEAC) indicating the presence of a $\mathrm{t}(14 ; 16)(\mathrm{q} 32 ; \mathrm{q} 23)$ plus an extra derivative chromosome 14 or 16 and additional signals for CCNDI, FRFG3/MMSET, MAF and IGH loci, which might indicate polyploidy. (c) General overview of a bone marrow smear stained for VS38c, specific for plasma cells, from case no. 4. The indicated panel shows a VS38c-positive cell with plasma cell morphology displaying a triple fusion of the probes for $I G H(\mathrm{SG})$ and $C C N D 1$ (SO) indicating the presence of a $\mathrm{t}(11 ; 14)(\mathrm{q} 13 ; \mathrm{q} 32)$ plus an extra derivative chromosome 11 or 14 (arrow heads). (d-f) MI-FISH/FICTION PCD IGH assay 2 includes probes for IGH, IRF4, IRTAI/2 and MAFB. (d) The interphase nucleus from case no. 11 shows a double fusion (arrows) of the probes for IGH (SO-SG) and IRF4 (TR) suggesting the presence of a t(6;14)(p25;q32) translocation, and one additional signal for IRTAl/2 (DEAC). (e) The interphase nucleus from case no. 12 shows a double fusion (arrows) of the probes for IGH (SO-SG) and MAFB (Cy5) indicating the presence of a $\mathrm{t}(14 ; 20)(\mathrm{q} 32 ; \mathrm{q} 12)$ translocation. (f) A VS38c-positive cell from case no. 4 shows a fusion of red and green signals which points to the intact $I G H$ locus (arrow), whereas the split signals suggest the presence of a translocation affecting IGH (arrow head). The extra green signal indicates the presence of an extra derivative chromosome 14. This signal pattern is in line with the results obtained with the PCD IGH assay 1 shown in c. The $I G H$ translocation corresponds to a t $(11 ; 14)$ as was shown applying the M-FICTION PCD IGH assay 1. Additionally, the M-FICTION PCD IGH assay 2 confirms the presence of an extra derivative chromosome, as was shown in c, and reveals that it corresponds to the der(11)t(11;14). (g-i) MI-FISH PCD 13q assay for the detection of chromosome 13 deletions including probes for the $R B 1$ gene, and the loci D13S319, D13S25 and D13S327. (g) Chromosome 13 from a normal control metaphase shows the regular signal constellation pattern. (h) Interphase nucleus from case no. 5 displays a signal constellation indicating monosomy 13. (i) The nucleus of case no. 10 displays a signal pattern indicating interstitial deletion in chromosomal band $13 \mathrm{q} 14$ with the loss of probes spanning $R B 1$, D13S319, and D13S25. 
translocations affecting $I R F 4$ and $M A F B$ respectively (Fig. 1d and e).

The partner gene involved in the $I G H$ translocation in the other four cases remained unidentified by the novel MI-FISH assays. One of the cases (no. 7) was subsequently shown to carry an $I G H-M Y C$ fusion. The lack of identifiable $I G H$ partners in the remaining cases was most likely due to the great number of loci involved in IGH rearrangements in MM. All had a prevalence of $\leq 1 \%$, and therefore were not included in the MI-FISH assays described here (7).

MI-FISH for the detection of 13 deletions in PCD. All $10 \mathrm{MM}$ (nos. 1-10), for which conventional cytogenetics did not show an aberrant karyotype, were investigated with the $13 q$ MI-FISH assay (Table I).

Three out of ten (nos. 5, 6 and 8) displayed a signal constellation indicating the loss of a complete chromosome 13 (Fig. 1h). Case no. 10 displayed a signal constellation pointing to an interstitial deletion of chromosomal band $13 \mathrm{q} 14$ with the loss of the RBI gene, and the markers D13S319 and D13S25 (Fig. 1i).

$M$-FICTION in PCD. Unstained bone marrow smears were available only for case no. 4 in this series. M-FICTION was applied using the same multicolor probes in combination with the plasma cell-specific MoAb VS38c. The results clearly showed that $I G H-C C N D I$ fusion was present exclusively in the plasma cell subset (VS38c-positive, Fig. 1c). A deletion affecting 13q was not found in this case. Plasma cells without $I G H$ alterations existed as well, most likely representing the nonmalignant plasma cell population. All evaluated cells lacking VS38c staining displayed normal signal constellations.

In conclusion, the detection of $I G H$ translocations and chromosome 13 deletions is important for the diagnostic and the clinical management of patients with PCD $(8,9)$. Recently, Wuilleme and colleagues showed that the MI-FISH approach is a sensitive method for the detection of hyperdiploidy in MM regardless of metaphase availability (21). Additionally, commercial suppliers have released some reliable probes for the detection of the most frequent chromosome aberrations in MM, such as del(13q)/-13, $\mathrm{t}(11 ; 14), \mathrm{t}(4 ; 14)$ and $\mathrm{t}(14 ; 14)$. However, these commercial probes are only available for a limited number of $I G H$ translocation partners and are not yet available as multicolor diagnostic sets.

Therefore, we designed a set of FISH probes for the detection of $I G H$ translocations and $13 \mathrm{q}$ deletions. We have shown the applicability of this probe set for multicolor interphase cytogenetics by means of MI-FISH and MFICTION. However, due to the versatility of the probe design, it was also possible to label them in a dual-color fashion in order to detect chromosomal breakpoints in a gene regardless of its partner chromosome by a break-apart approach, or to combine them with other commercially available or selfmade FISH probes, e.g. for the $I G$ light chain loci.

Thus, with these novel MI-FISH and M-FICTION assays, we have provided new reliable tools for the rapid and sensitive detection of those chromosomal abnormalities with prognostic implications affecting the $I G H$ loci and chromosome 13 in the plasma cell compartment and at the single-cell level. These novel means for the cytogenetic analysis of plasma cell neoplasms may be applied for initial characterization, evaluation of follow-up and monitoring of minimal residual disease in plasma cell dyscrasias.

\section{Acknowledgements}

The authors thank the medical, scientific and technical staff from the Department of Genetics of the University of Navarra, Pamplona, Spain, and from the Institute of Human Genetics, Kiel, Germany. All experiments conducted in the present study complied with the current international laws. This study was partially supported by G03/136 Red tematica FIS, the Spanish Ministry of Health, the Health Department of the Gobierno de Navarra (946/2005) and the European Union. Borja Sáez is a scholar of the Gobierno de Navarra.

\section{References}

1. Bergsagel PL and Kuehl WM: Chromosome translocations in multiple myeloma. Oncogene 20: 5611-5622, 2001

2. Zojer N, Konigsberg R, Ackermann J, Fritz E, Dallinger S, Kromer E, Kaufmann H, Riedl L, Gisslinger H, Schreiber S, Heinz R, Ludwig H, Huber H and Drach J: Deletion of $13 q 14$ remains an independent adverse prognostic variable in multiple myeloma despite its frequent detection by interphase fluorescence in situ hybridization. Blood 95: 1925-1930, 2000.

3. Avet-Louseau H, Daviet A, Sauner S and Bataille R: Chromosome 13 abnormalities in multiple myeloma are mostly monosomy 13. Br J Haematol 111: 1116-1117, 2000.

4. Shaughnessy J, Tian E, Sawyer J, Bumm K, Landes R, Badros A, Morris C, Tricot G, Epstein J and Barlogie B: High incidence of chromosome 13 deletion in multiple myeloma detected by multiprobe interphase FISH. Blood 96: 1505-1511, 2000.

5. Avet-Loiseau H, Li JY, Morineau N, Facon T, Brigaudeau C, Harousseau JL, Grosbois B and Bataille R: Monosomy 13 is associated with the transition of monoclonal gammopathy of undetermined significance to multiple myeloma. Intergroupe Francophone du Myelome. Blood 94: 2583-2589, 1999.

6. Fonseca R, Barlogie B, Bataille R, Bastard C, Bergsagel PL, Chesi M, Davies FE, Drach J, Greipp PR, Kirsch IR, Kuehl WM, Hernandez JM, Minvielle S, Pilarski LM, Shaughnessy JD Jr, Stewart AK and Avet-Loiseau H: Genetics and cytogenetics of multiple myeloma: a workshop report. Cancer Res 64: 1546-1558, 2004.

7. Kuehl WM and Bergsagel PL: Multiple myeloma: evolving genetic events and host interactions. Nat Rev Cancer 2: 175-187, 2002 .

8. Fonseca R, Blood E, Rue M, Harrington D, Oken MM, Kyle RA, Dewald GW, Van Ness B, Van Wier SA, Henderson KJ, Bailey RJ and Greipp PR: Clinical and biologic implications of recurrent genomic aberrations in myeloma. Blood 101: 4569-4575, 2003.

9. Gertz MA, Lacy MQ, Dispenzieri A, Greipp PR, Litzow MR, Henderson KJ, Van Wier SA, Ahmann GJ and Fonseca R: Clinical implications of $\mathrm{t}(11 ; 14)(\mathrm{q} 13 ; \mathrm{q} 32), \mathrm{t}(4 ; 14)(\mathrm{p} 16.3 ; \mathrm{q} 32)$, and -17 p13 in myeloma patients treated with high-dose therapy. Blood 106: 2837-2840, 2005.

10. Weber-Matthiesen K, Winkemann M, Muller-Hermelink A, Schlegelberger B and Grote W: Simultaneous fluorescence immunophenotyping and interphase cytogenetics: a contribution to the characterization of tumor cells. J Histochem Cytochem 40: 171-175, 1992.

11. Martin-Subero JI, Chudoba I, Harder L, Gesk S, Grote W, Novo FJ, Calasanz MJ and Siebert R: Multicolor-FICTION: expanding the possibilities of combined morphologic, immunophenotypic, and genetic single cell analyses. Am J Pathol 161: 413-420, 2002.

12. Jackson N, Lowe J, Ball J, Bromidge E, Ling NR, Larkins S, Griffith MJ and Franklin IM: Two new IgA1-kappa plasma cell leukaemia cell lines (JJN-1 \& JJN-2) which proliferate in response to $\mathrm{B}$ cell stimulatory factor 2. Clin Exp Immunol 75: 93-99, 1989. 
13. Sonoki T, Harder L, Horsman DE, Karran L, Taniguchi I, Willis TG, Gesk S, Steinemann D, Zucca E, Schlegelberger B, Sole F, Mungall AJ, Gascoyne RD, Siebert R and Dyer MJ: Cyclin D3 is a target gene of $\mathrm{t}(6 ; 14)(\mathrm{p} 21.1 ; \mathrm{q} 32.3)$ of mature Bcell malignancies. Blood 98: 2837-2844, 2001.

14. Martin-Subero J, Harder L, Gesk S, Schlegelberger B, Grote W, Martinez-Climent J, Dyer M, Novo F, Calasanz M and Siebert R: Interphase FISH assays for the detection of translocations with breakpoints in immunoglobulin light chain loci. Int J Cancer 98: 470-474, 2002.

15. Bentz M, Cabot G, Moos M, Speicher MR, Ganser A, Lichter P and Dohner H: Detection of chimeric BCR-ABL genes on bone marrow samples and blood smears in chronic myeloid and acute lymphoblastic leukemia by in situ hybridization. Blood 83: 1922-1928, 1994.

16. Hatzivassiliou G, Miller I, Takizawa J, Palanisamy N, Rao PH, Iida S, Tagawa S, Taniwaki M, Russo J, Neri A, Cattoretti G, Clynes R, Mendelsohn C, Chaganti RS and Dalla-Favera R: IRTA1 and IRTA2, novel immunoglobulin superfamily receptors expressed in B cells and involved in chromosome 1q21 abnormalities in B cell malignancy. Immunity 14: 277-289, 2001.

17. Bergsagel PL, Chesi M, Nardini E, Brents LA, Kirby SL and Kuehl WM: Promiscuous translocations into immunoglobulin heavy chain switch regions in multiple myeloma. Proc Natl Acad Sci USA 93: 13931-13936, 1996.
18. Yoshida S, Nakazawa N, Iida S, Hayami Y, Sato S, Wakita A, Shimizu S, Taniwaki M and Ueda R: Detection of MUM1/ IRF4-IgH fusion in multiple myeloma. Leukemia 13: 1812-1816, 1999.

19. Chesi M, Bergsagel PL, Shonukan OO, Martelli ML, Brents LA, Chen T, Schrock E, Ried T and Kuehl WM: Frequent dysregulation of the c-maf proto-oncogene at $16 \mathrm{q} 23$ by translocation to an Ig locus in multiple myeloma. Blood 91: 4457-4463, 1998.

20. Hanamura I, Iida S, Akano Y, Hayami Y, Kato M, Miura K, Harada S, Banno S, Wakita A, Kiyoi H, Naoe T, Shimizu S, Sonta SI, Nitta M, Taniwaki M and Ueda R: Ectopic expression of MAFB gene in human myeloma cells carrying $(14 ; 20)$ (q32;q11) chromosomal translocations. Jpn J Cancer Res 92: 638-644, 2001

21. Wuilleme S, Robillard N, Lode L, Magrangeas F, Beris H, Harousseau JL, Proffitt J, Minvielle S and Avet-Loiseau H: Ploidy, as detected by fluorescence in situ hybridization, defines different subgroups in multiple myeloma. Leukemia 19: 275-278, 2005. 